\title{
Sensitivity Analysis of Brinell Hardness Number to Material Properties of Structural Steel: A Numerical Study
}

\author{
S.P.L. Madhumali, J.A.S.C. Jayasinghe, C.S. Bandara and A.J. Dammika
}

\begin{abstract}
Hardness is not a fundamental property of a material but it is related to the elastic and plastic properties of the material. Hardness of a material can be determined from indentation hardness tests. Brinell hardness test is one of the commonly used macro-indentation hardness test types to quantify the hardness of a material. In this study, the sensitivity of Brinell Hardness Number (BHN) to the material properties of structural steels that exhibit a plastic plateau in their true stress-strain curve is analysed. Four basic structural steel material properties, Young's modulus $(E)$, yield strength $\left(\sigma_{y}\right)$, ratio $(\alpha)$ between the strain at beginning-point of strain hardening $\left(\varepsilon_{s t}\right)$ and the yield strain $\left(\varepsilon_{y}\right)$ and strain hardening exponent $(n)$ are considered for the sensitivity analysis. By identifying the sensitivity of hardness to these material properties, an inverse analysis method based on a hardness test can be developed to identify the unknown steel materials. For a given material combination, the loaddisplacement curve of macro-indentation can be developed using the Finite Element (FE) simulation. For that, a 2D axisymmetric nonlinear FE model is developed using finite element software package $A B A Q U S$ and validated using past experimental data. Then BHNs are calculated for selected material combinations and variation of BHN with each material property is obtained. Considering the relationships between material properties and BHN, the sensitivity of BHN to each material property is calculated. Finally, a comparison is made for the sensitivity of hardness by considering all four material properties.
\end{abstract}

Keywords: Axisymmetric FE simulation, Brinell hardness number, Macro-indentation test, Material properties, Sensitivity analysis

\section{Introduction}

Due to the effect of load, environmental erosion, material ageing, accidental bumping, and many other factors, in-service civil structures ultimately lead to structural damages [1] - [3]. By considering this, structural health monitoring and non-destructive assessment methods have been developed in the past two decades to manage civil engineering structures more efficiently [4], [5]. Since the real properties of materials are changing with time, identification of the material properties of structural members plays an important role in the structural damage assessment process.

Though there are many ways available to evaluate material properties of engineering metals, such as brittle coating, neutron diffraction [6], X-ray method [7], centre-hole drilling [8], magnetic techniques [9], eddy current techniques [10], small punch test (SPT) and ball-on-three-balls (B3B) test [11], etc., most of these techniques are complex, destructive procedures and expensive. Therefore, in recent years, it has become seriously important to determine the material properties of structural members in a semi-destructive or nondestructive way. It must be applicable to the existing structures for structural health monitoring purposes.

Depth-sensing instrumented indentation test or hardness test is one of very easy, quick and inexpensive, semi destructive testing

Eng. (Miss) S. P.L. Madhumali, BSc Eng. (Hons)

(Peradeniya), Temporary Instructor, Department of Civil

Engineering, University of Peradeniya, Sri Lanka.

Email:madhumalil1995@eng.pdn.ac.lk

(iD) https://orcid.org/0000-0001-9962-7791

Eng. (Dr.) J. A. S. C. Jayasinghe, BSc Eng. (Hons)

(Peradeniya), M Eng. (AIT), PhD. (Tokyo), Senior Lecturer,

Department of Civil Engineering, University of Peradeniya, Sri Lanka.

Email:supunj@pdn.ac.lk

(iD http://orcid.org/0000-0003-1054-9358

Eng. (Dr.) C.S. Bandara, C Eng., MIE(SL), BSc

Eng. (Peradeniya), MSc Eng. (Peradeniya), PhD.

(Peradeniya), Senior Lecturer in Department of Civil

Engineering, University of Peradeniya, Sri Lanka.

Email:csbandara@eng.pdn.ac.lk

(D) http://orcid.org/0000-0003-4141-8983

Eng. (Dr.) A. J. Dammika, BSc Eng. (Hons) (Peradeniya),

$M$ Eng. (AIT), PhD. (Saitama), Senior Lecturer, Department

of Civil Engineering, University of Peradeniya,

Sri Lanka.

Email:dammikaaj@pdn.ac.lk

(iD) $h$ ttps://orcid.org/0000-0002-2587-3743 
techniques which can be used to determine the unknown material properties. The characteristics that exhibit in the indentation load-displacement curve have a good relationship with the properties of the material such as Young's modulus, yield strength, strain hardening exponent, residual stress-strain, etc. [12] - [30].

Indentation hardness is determined by indenting a surface using a harder surface to form a permanent impression with plastic deformation. Based on the applied load and the penetration depth, indentation hardness can be categorized as macro, micro, and nano. Table 1 gives the ranges of applied loads $(L)$ and penetration depths $(h)$ specified by ISO $14577-1$ norm for determining the above three categories [12].

Table 1 - Hardness Testing Scales Defined by ISO 14577-1 [12]

\begin{tabular}{|c|c|c|}
\hline Scale & $\begin{array}{c}\text { Load Range }(\boldsymbol{L}) / \\
(N)\end{array}$ & $\begin{array}{c}\text { Penetration } \\
\text { Range }(\boldsymbol{h}) /(\mu \mathrm{m})\end{array}$ \\
\hline Macro & $2<L<30,000$ & Not-specified \\
\hline Micro & $L<2$ & $h>0.2$ \\
\hline Nano & Not-specified & $h<0.2$ \\
\hline
\end{tabular}

To determine the properties of the damaged structural members in structural health monitoring, macro-indentation is more suitable than others since micro and nano indentations are used to characterize the material properties of microscale and nanoscale objects such as bulk materials, thin films and coatings, integrated circuits (IC), etc. [13] - [16].

Brinell, Meyer, Rockwell, and Vickers are commonly used macro-indentation hardness tests. Based on the shape of the indenter, these macro-indentation tests can be divided into spherical indentation and sharp indentation. Spherical indentation loading-unloading curves contain more information on the material properties than those from a sharp indentation test [17]. In addition to that, spherical indentation has many advantages over a sharp indentation in the determination of material elastoplastic properties [13]. In the present work, we focus on the Brinell hardness test since it is the most used spherical indentation test type.

Spherical indentation has been used by many researchers to determine material elastic and plastic properties [13], [18] - [25]. However, most of them are valid only for the materials without a plastic plateau in their true stressstrain behaviour [21] - [24]. The available methods for determining material properties of the materials with a plastic plateau in their true stress-strain behaviour such as, structural steel, are limited [25], [26].

Structural steels exhibit a plastic plateau in their true stress-strain curve. It is a plastic instability associated with the unpinning of dislocations from the interstitial elements in solid solution [27]. It initiates from the "upper yield stress" and ends at the beginning point of strain hardening $\left(\varepsilon_{s t}\right)$. Figure 1 illustrates the typical true stress-strain curve of structural steel.

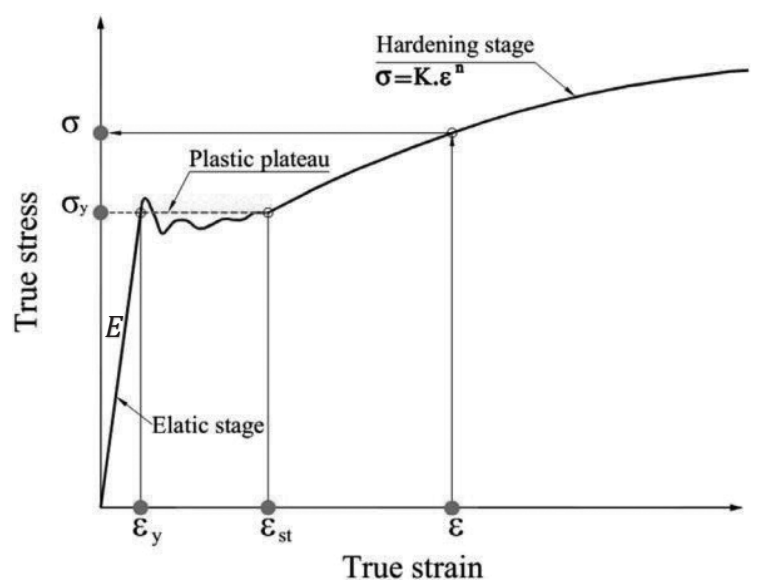

Figure 1 - Schematic Illustration of Typical True Stress-Strain Curve for Structural Steel

The plastic plateau in the structural steel true stress-strain curve (solid curve between $\varepsilon_{y}$ and $\varepsilon_{s t}$ in Figure 1) can be assumed as a perfectly plastic plateau (dotted line in Figure 1) to simplify the steel material model [26], [28]. Then, the stress-strain curve of structural steel can be expressed as Eq. (1) [26].

$\sigma= \begin{cases}E \varepsilon & ; \varepsilon \leq \varepsilon_{y} \\ \sigma_{y} & ; \varepsilon_{y} \leq \varepsilon \leq \varepsilon_{s t} \\ \sigma_{y}\left[1+\frac{E\left(\varepsilon-\varepsilon_{s t}\right)}{\alpha \sigma_{y}}\right]^{n} & ; \varepsilon>\varepsilon_{s t}\end{cases}$

where,

$$
\begin{aligned}
& E=\text { Young's modulus } \\
& \sigma_{\mathrm{y}}=\text { Initial yield stress } \\
& n=\text { Strain hardening exponent } \\
& \alpha=\frac{\varepsilon_{s t}}{\varepsilon_{y}}
\end{aligned}
$$

This study aims to analyse the sensitivity of indentation hardness to the structural steel material properties, Young's modulus $(E)$, yield strength $\left(\sigma_{y}\right)$, ratio $(\alpha)$ between the strain at beginning-point of strain hardening $\left(\varepsilon_{s t}\right)$ and 
the yield strain $\left(\varepsilon_{y}\right)$ and strain hardening exponent $(n)$. This sensitivity analysis will be helpful to develop a simple and cost-effective method based on hardness test to determine the unknown material properties of structural steel which can be easily used in the field. From that, the aforementioned problem can be addressed in the future.

Here, Brinell Hardness Number (BHN) is used to quantify the indentation hardness since $\mathrm{BHN}$ can be easily obtained from experimental Brinell hardness test within a short period of time. For a target metal specimen $\mathrm{BHN}$ can be found within acceptable limit from the numerical indentation simulations [29]. Therefore, the present study is fully based on a numerical approach. For a given material property, indentation load-displacement curves can be developed using finite element simulation. To model the indentation hardness test, two dimensional (2D) axisymmetric finite element simulation is used.

The summarized methodology is as follows. First, the Finite Element (FE) model is developed and validated using past experimental data [13]. Next, indentation loaddisplacement curves are obtained by varying the material properties, $E, \sigma_{y}, \alpha$ and $n$. Here, to check the sensitivity of $\mathrm{BHN}$ to each material property, one material property is changed by fixing other material properties. Then, BHN is calculated for each material combination using indentation load-displacement curves and the variations of $\mathrm{BHN}$ with material properties are plotted. Finally, the sensitivity of BHN to each material property is calculated. Thereby, a comparison for the sensitivity of $\mathrm{BHN}$ to the material properties is made.

\section{Finite Element Modelling of Macro-Indentation Simulation}

The spherical indentation simulation is done using commercial nonlinear finite element (FE) analysis software package ABAQUS to obtain the load-displacement curves of macroindentation for different material combinations. For the simulation of the hardness test, mainly two types of FE models can be used as 2D axisymmetric and 3D solid models. In this study, a 2D axisymmetric FE model is used to simulate the spherical indentation procedure with proper boundary conditions, considering the symmetries of both the geometry and the loading condition; see Figure 2 for the developed 2D ball indentation FE model.
In this indentation simulation, reduced integration and hourglass control elements are used with the application of the Von-Mises plasticity model and the contact theory. Since the hardness of the indenter is very high compared to the specimens, a rigid ball indenter is employed for indentation simulation and a rigid movable analytical surface is used to model the indenter. In addition to that, the computational time can be reduced by using a rigid indenter instead of a deformable indenter, because a $2 \mathrm{D}$ rigid indenter has three degrees of freedom at the reference point to control its behaviour [31].
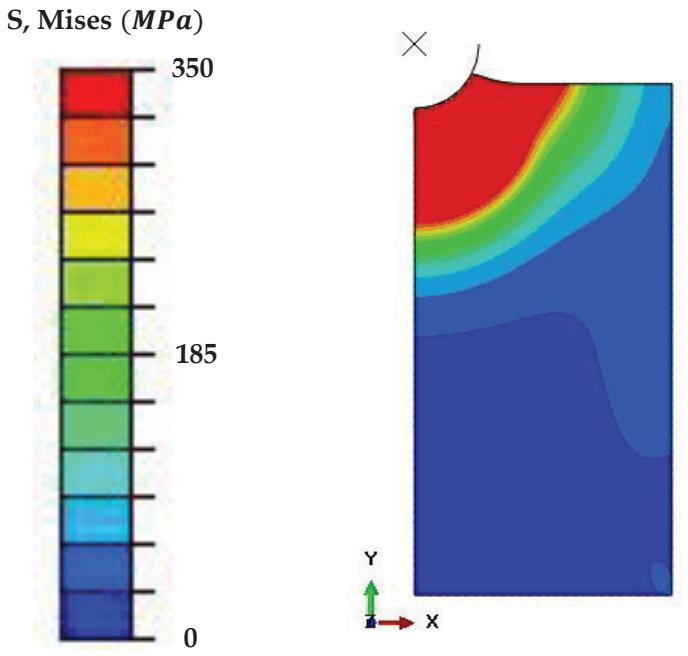

Figure 2 - 2D Ball indentation

The true stress-strain curves of different combinations of material properties are employed for the FE simulation. The specimen size should be selected such that boundary condition effects can be neglected. For that, sensitivity simulations were carried out by varying specimen diameter and depth for $1 \mathrm{~mm}$ indentation depth and specimen size was selected as $20 \mathrm{~mm}$ diameter, $20 \mathrm{~mm}$ depth cylindrical specimen. The element type used for the specimen is 'CAX4R'. The meshes on the specimen are created such that they are finer near the indentation area and are coarser in the other parts of the specimen as shown in Figure 3.

The static general step is used with a time period of one second for each loading and unloading step. The penalty tangential behaviour is used as the interaction property between the indenter and the specimen with a 0.1 friction coefficient [25]. Then, a surface-tosurface contact interaction is created between them such that the outer surface of the indenter acts as a master surface and the top surface of 
the specimen acts as a slave surface. Though the value of Poisson's ratio does not affect the indentation load-displacement curve, it is taken as 0.3 [30] for all material combinations.

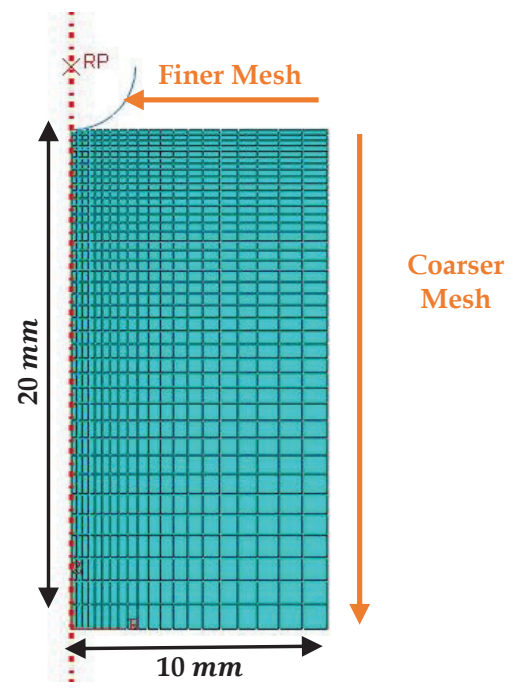

Figure 3 - Finite Element Mesh

The boundary conditions are applied such that a displacement-controlled indentation by allowing the rigid indenter to move along the $y$ axis and penetrated up to the maximum depth into the specimen. The nodes on the $y$ axis move only along the axis itself and the bottom of the specimen is fixed. See Figure 4 for the basic geometry and assembly of the 2D FE model with applied boundary conditions.

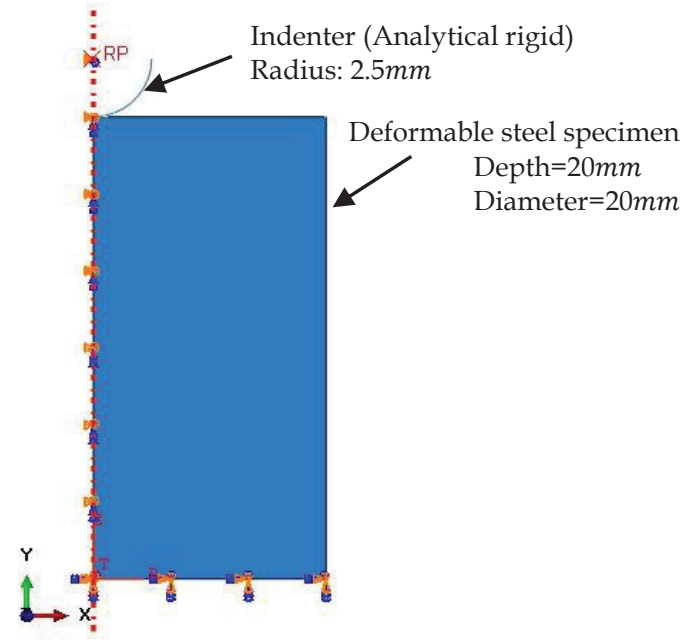

Figure 4 - Basic Geometry and Assembly of the 2D FE Model in ABAQUS

\section{Validation of FE Model with Past Test Results}

The validation of the ABAQUS FE model is done by using past experimental data of a ball indentation. A533-B steel with Young's modulus (E) $210 \mathrm{GPa}$, yield strength $\left(\sigma_{y}\right) 400$
$M P a$ and strain hardening exponent $(n) 0.127$ with $0.788 \mathrm{~mm}$ radius rigid ball indenter is used for the validation. The maximum penetration depth is taken as $0.287 \mathrm{~mm} \times R$ [13].

The comparison between the developed loaddisplacement curve for 2D ball indentation and that from the past experimental data is shown in Figure 5. It shows that both experimental and numerical load-displacement curves are wellmatched with each other. The Mean Absolute Percentage Error (MADE) between two curves is calculated as $1.91 \%$ and it is in the acceptable level. Therefore, it was decided to use the developed 2D axisymmetric model for this study.

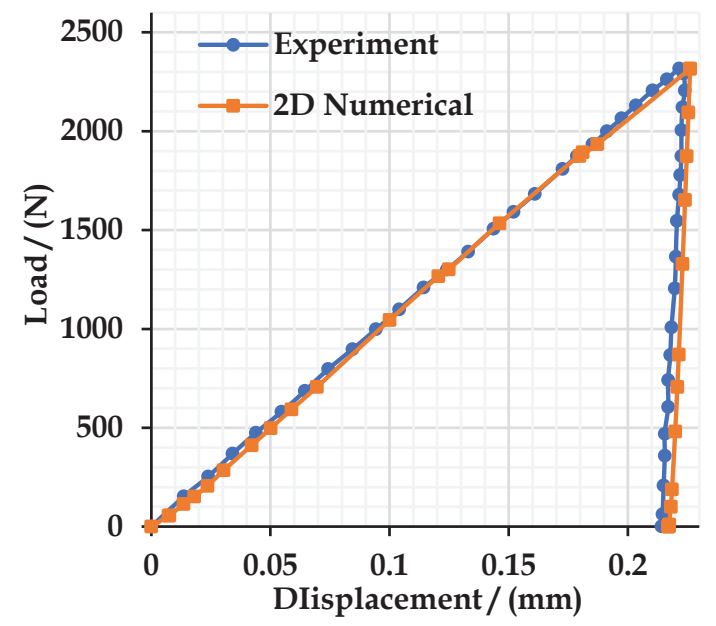

Figure 5 - Validation of Ball Indentation Model with Past Experimental Results

\section{Sensitivity of Brinell Hardness Number (BHN) to Structural Steel Material Properties}

In this section, the sensitivity of BHN to each structural steel material property $\left(E, \sigma_{y}, \alpha\right.$ and $\left.n\right)$ is analysed. The ranges of the material properties are selected by considering the structural steel material property ranges. Table 2 gives the selected material property values for defining material combinations in this study.

Table 2 - Parameters Used for Defining the Material Combinations

\begin{tabular}{|c|c|}
\hline $\begin{array}{c}\text { Material } \\
\text { Parameter }\end{array}$ & Selected values \\
\hline$E(G P a)$ & $190,195,200,205,210$ \\
\hline$\sigma_{y}(M P a)$ & $275,300,325,350,375,400$ \\
\hline$n$ & $0,0.1,0.2,0.3,0.4,0.5$ \\
\hline$\alpha$ & $7,10,15,16,20,23$ \\
\hline
\end{tabular}


BHN is calculated for all the material combinations by using their numerical loaddisplacement curves which are obtained from the developed validated $2 \mathrm{D}$ axisymmetric FE models. The equation used for calculating BHN is given in Eq. (2).

$$
B H N=\frac{2 P}{\pi D\left(D-\sqrt{D^{2}-d^{2}}\right)}=\frac{P}{\pi D t}
$$

where,

$$
\begin{aligned}
& P=\text { Applied load in kilograms }(\mathrm{kg}) \\
& D=\text { Diameter of indenter }(\mathrm{mm}) \\
& d=\text { Diameter of the indentation }(\mathrm{mm}) \\
& t=\text { Indentation depth }(\mathrm{mm})
\end{aligned}
$$

Usually, no measuring unit is used for BHN. In calculating BHN, the standard applied load for $5 \mathrm{~mm}$ diameter indenter is $750 \mathrm{~kg}$ [32].

The sensitivity of BHN concerning each structural steel material property is calculated using the sensitivity definition provided in mathematics. Mathematically, sensitivity is quantitatively defined as follows [33].

$\begin{aligned} & \text { Sensitivity of } \\ & y \text { with respect }\end{aligned}=\frac{\% \text { change in } y(d y / y)}{\% \text { change in } x(d x / x)}$

The following example describes the sensitivity definition more clearly.

Let's consider the variation of $y$ with $x$ given by the function $y=f(x)$ as illustrated in Figure 6 and derivative of $y$ is given by $\frac{d y}{d x}=f^{\prime}(x)$. Then, the percentage change in $y$ is given by Eq. (4) and the sensitivity of $y$ with respect to $x$ is given by Eq. (5) as follows.

$$
\begin{gathered}
\frac{d y}{y}=\frac{f^{\prime}(x)}{f(x)} d x \\
\frac{(d y / y)}{(d x / x)}=\frac{f^{\prime}(x)}{f(x)} x
\end{gathered}
$$

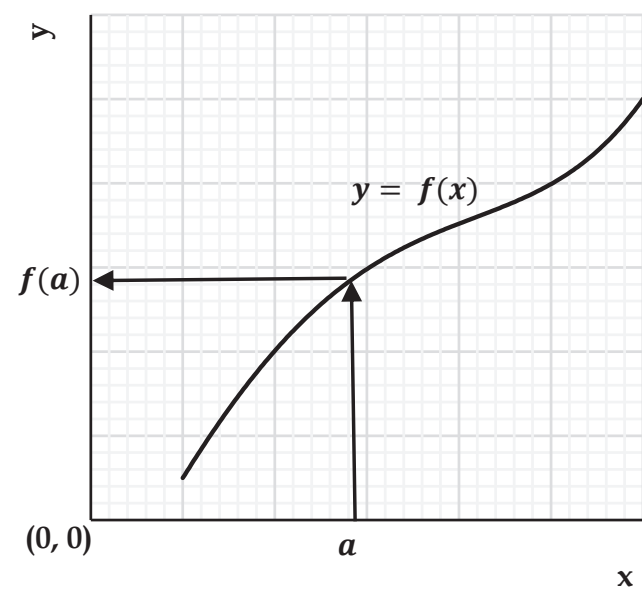

Figure 6 - Illustration of the function $y=f(x)$

For a given point in $x$, the sensitivity of $y$ with respect to $x$ can be described as follows.

If $x=a, y=f(a)$ and $\frac{d y}{d x}=f^{\prime}(a)$, then,

$$
\begin{aligned}
& \text { Sensitivity of } y \text { with } \\
& \text { respect to } x \text { at } x=a
\end{aligned} \quad=\frac{f^{\prime}(a)}{f(a)} \text { a }
$$

That means, if $x$ changes by 1 unit, $y$ is going to change by $\frac{f \prime(a)}{f(a)} a$ units at $x=a$. Here, the sensitivity of $y$ can be a positive value or a negative value. If it is a positive value, that means for 1 unit change in $x, y$ is going to change in the same direction of $x$ and if it is a negative value, that means for 1 unit change in $x, y$ is going to change in the opposite direction of $x$. By using the above definition, the sensitivity of BHN with respect to each structural steel material property is calculated.

\subsection{Sensitivity of BHN to Young's Modulus (E)}

To identify the behaviour of BHN with Young's modulus $(E)$, steel specimens with $\sigma_{y}=350$ $M P a, n=0.2$ and $\alpha=7$ are employed with different Young's modulus values; 190 GPa, 195 $G P a, 200 G P a, 205 G P a$ and $210 G P a$. Figure 7 illustrates the load-displacement curves obtained from the validated FE model for different Young's modulus values. From Figure 7 , it can be seen that the maximum value of the loading curve increases with the increasing of the Young's modulus of the structural steel material. 


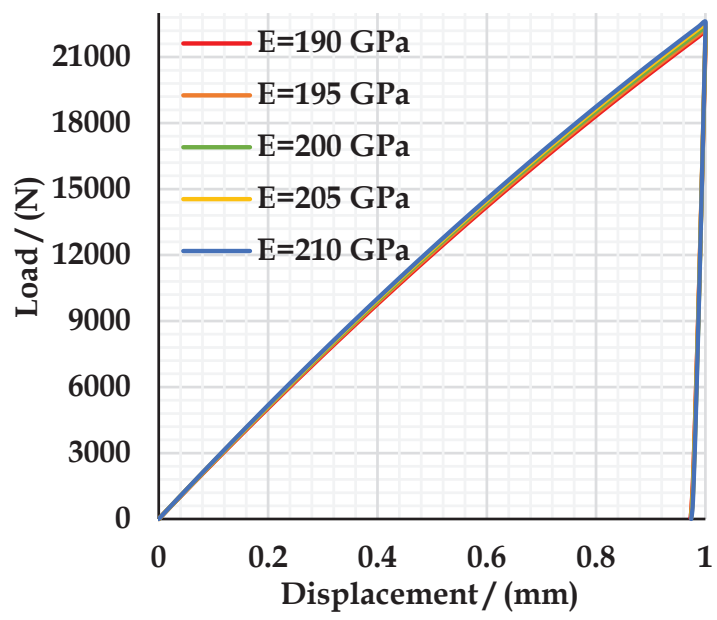

Figure 7 - Load-Displacement Curves for different Young's Modulus Values (for $\sigma_{y}=$ $350 M P a, n=0.2$ and $\alpha=7$ )

Using Eq. (2) and above load-displacement curves, BHN is calculated for structural steel materials with different Young's modulus values. The variation of BHN with the Young's modulus is shown in Figure 8. From the variation, it can be said that there is a good power relationship between the Young's modulus of structural steel material and the BHN.

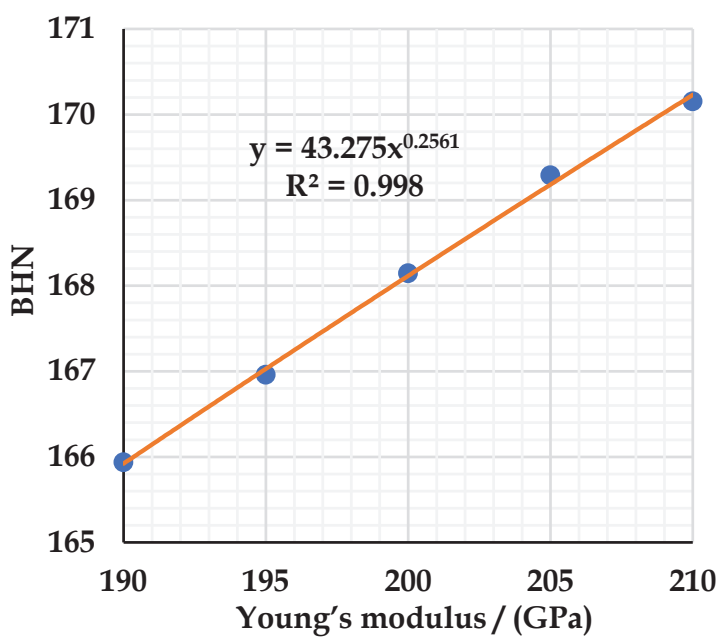

Figure 8 - Variation of BHN with the Young's Modulus

Considering Eq. (3), the sensitivity of BHN to the Young's modulus is calculated as 0.2561. That means if the Young's modulus increases by 1 unit, BHN is going to increase by 0.2561 units for all Young's modulus values. Hence, it can be said that the sensitivity of BHN to the Young's modulus is a constant for all structural steel materials. See Figure 9 for the variation of the sensitivity of BHN to the Young's modulus.

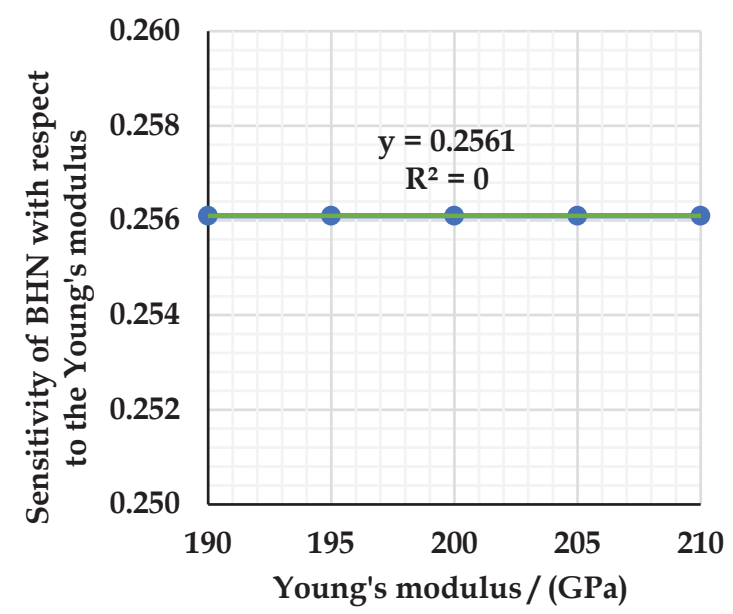

Figure 9 - Variation of Sensitivity of BHN to the Young's Modulus

\subsection{Sensitivity of BHN to the Yield Strength $\left(\sigma_{y}\right)$}

Steel specimens with $E=210 \mathrm{GPa}, n=0.2$ and $\alpha=7$ are employed with the different yield strength $\left(\sigma_{y}\right)$ values, $275 M P a, 300 M P a, 325$ $M P a, 350 M P a, 375 M P a$ and $400 M P a$ to identify the behaviour of BHN with the yield strength of the structural steel material. The load-displacement curves obtained from the validated FE model for different yield strength values are shown in Figure 10. From the variation of load-displacement curves, it can be said that the maximum value of the loading curve increases with the increasing of the yield strength of the material.

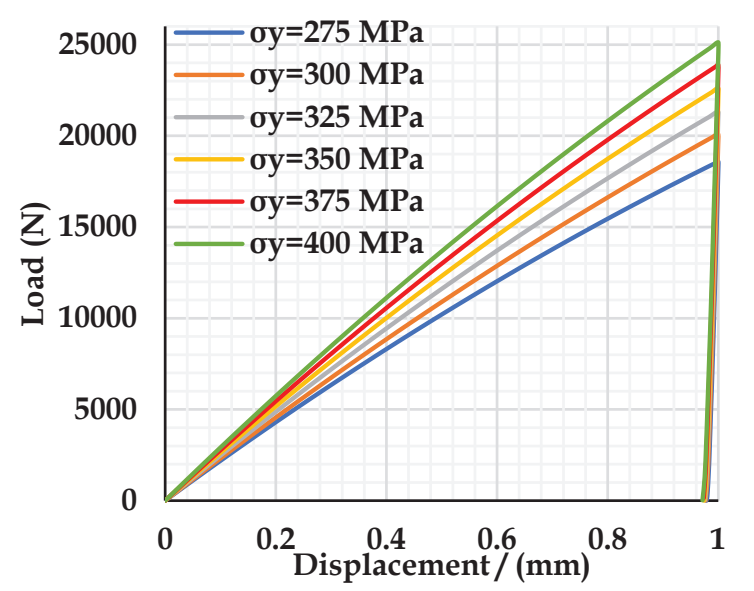

Figure 10 - Load-Displacement Curves for different Yield Strength Values (for $E=$ $210 G P a, n=0.2$ and $\alpha=7$ )

By using the above load-displacement curves and Eq. (2), BHNs are calculated for structural steel materials with different yield strength values. The variation of BHN with the yield strength is shown in Figure 11. It shows that there is a good linear relationship between the yield strength of the steel material and the BHN. 


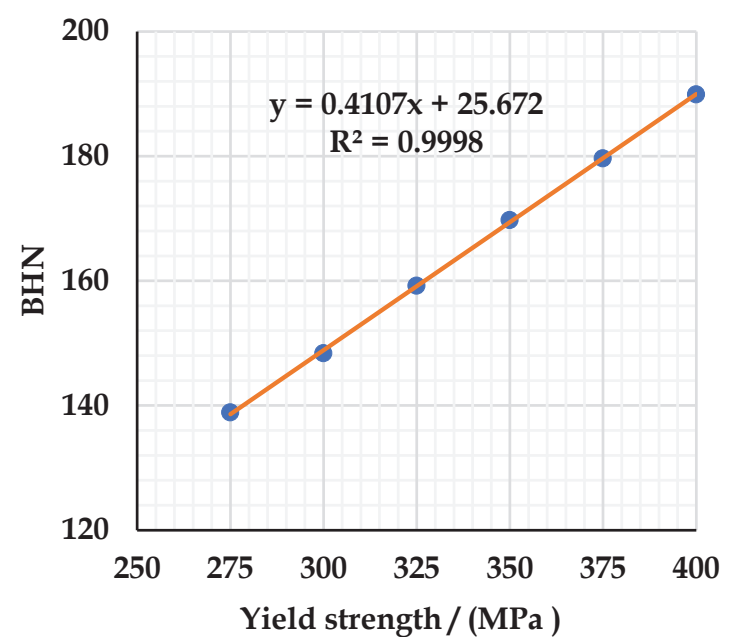

Figure 11 - Variation of BHN with the Yield Strength

According to Eq. (3), the sensitivity of BHN to the yield strength is obtained as $\frac{0.4107 \sigma_{y}}{0.4107 \sigma_{y}+25.672}$. That means if the yield strength increases by 1 unit at $\sigma_{y}=\sigma_{y_{0}}, \mathrm{BHN}$ is going to increase by $\frac{0.4107 \sigma_{y_{0}}}{0.4107 \sigma_{y_{0}}+25.672}$ units. See Figure 12 for the variation of the sensitivity of BHN to the yield strength for different yield strength values. It can be seen that the sensitivity of BHN to the yield strength increases with the increasing of the yield strength of the material.

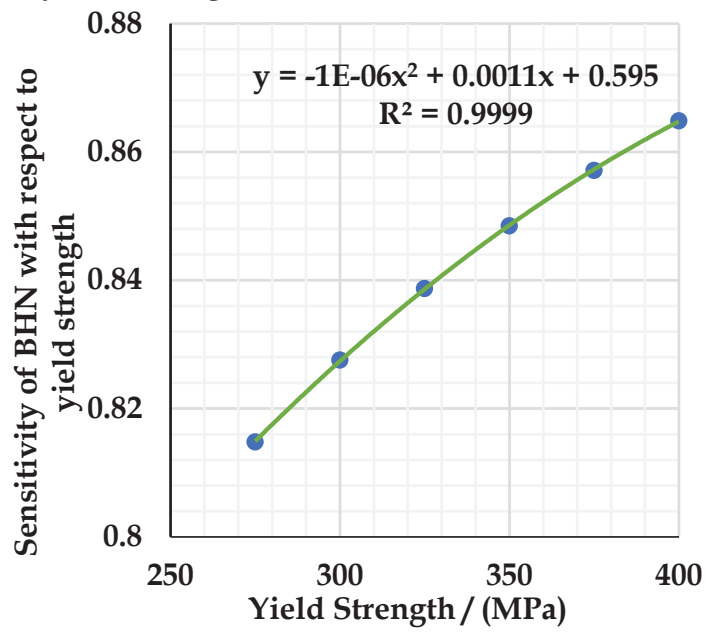

Figure 12 - Variation of Sensitivity of BHN to the Yield Strength

4.3 Sensitivity of BHN to the Ratio ( $\alpha$ ) between the Strain at Beginning-Point of Strain Hardening $\left(\varepsilon_{s t}\right)$ and the Yield strain $\left(\varepsilon_{y}\right)$ To identify the behaviour of BHN with the $\alpha$ value, steel specimens with $E=210 G P a, \sigma_{y}=$ $350 \mathrm{MPa}$ and $n=0.2$ are employed with different $\alpha$ values, 7, 10, 15, 16, 20 and 23. Figure 13 shows the load-displacement curves obtained from the validated FE model for different $\alpha$ values.

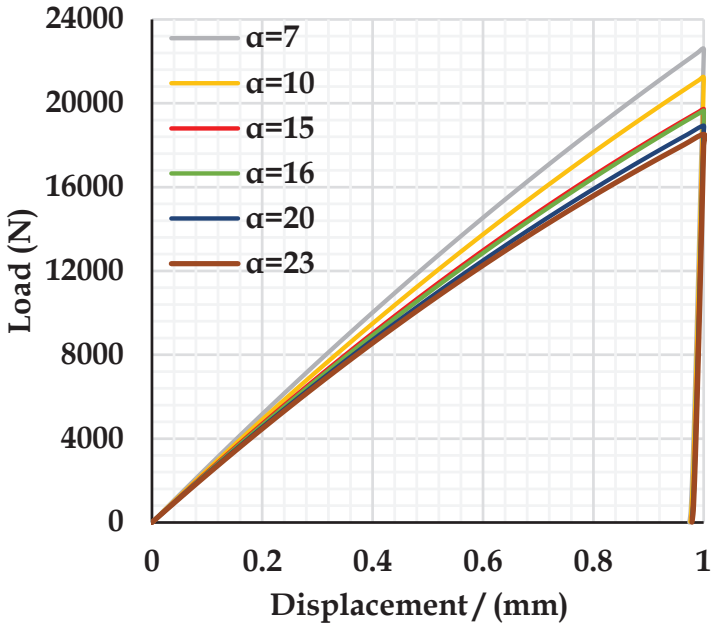

Figure 13 - Load-displacement Curves for different $\alpha$ Values (for $E=210 G P a, \sigma_{y}=350$ $M P a$ and $n=0.2$ )

By considering the variation of loaddisplacement curves, it can be said that the maximum value of the loading curve decreases with the increasing of the $\alpha$ value of the steel material.

Then BHNs are calculated for structural steel materials with different $\alpha$ values using Eq. (2). The relevant data obtained from the numerical load-displacement curves is shown in Figure 13. The variation of BHN with the $\alpha$ value is shown in Figure 14. It shows that there is a good power relationship between the $\alpha$ value of the steel material and the BHN.

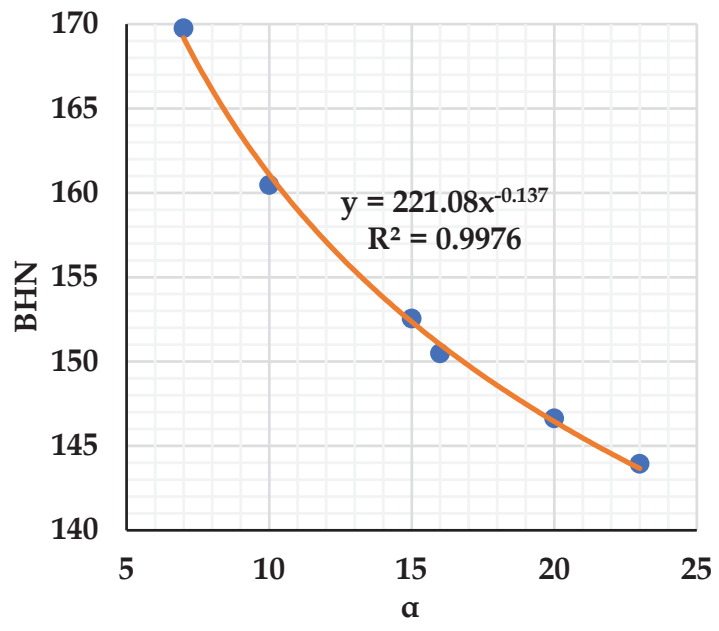

Figure 14 - Variation of BHN with the $\alpha$ Value

Eq. (3) is used to calculate the sensitivity of BHN to the $\alpha$ value and it is obtained as -0.137 . That means if the $\alpha$ value increases by 1 unit, $\mathrm{BHN}$ is going to decrease by 0.137 units for all $\alpha$ values. Therefore, it can be said that the sensitivity of $\mathrm{BHN}$ to the $\alpha$ value is a constant for all structural steel materials. The variation 
of the sensitivity of BHN to the $\alpha$ value for different $\alpha$ values is shown in Figure 15.

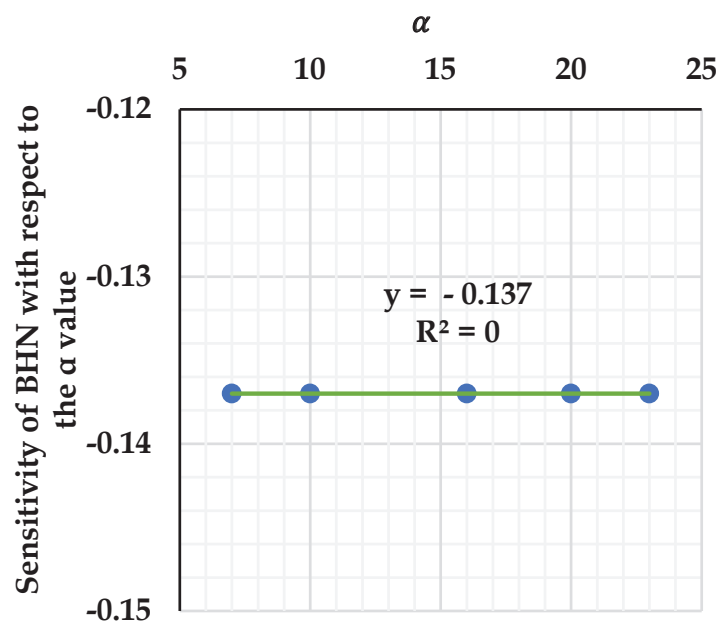

Figure 15 - Variation of Sensitivity of BHN to the $\alpha$ Value

4.4 Sensitivity of BHN to the Strain Hardening Exponent $(n)$

Steel specimens with $E=210 G P a, \sigma_{y}=350$ $M P a$ and $\alpha=7$ are employed with different strain hardening exponent $(n)$ values, $0,0.1,0.2$, $0.3,0.4$ and 0.5 to identify the behaviour of BHN with the strain hardening exponent. Figure 16 shows the load-displacement curves obtained from the validated FE model for different strain hardening exponent values.

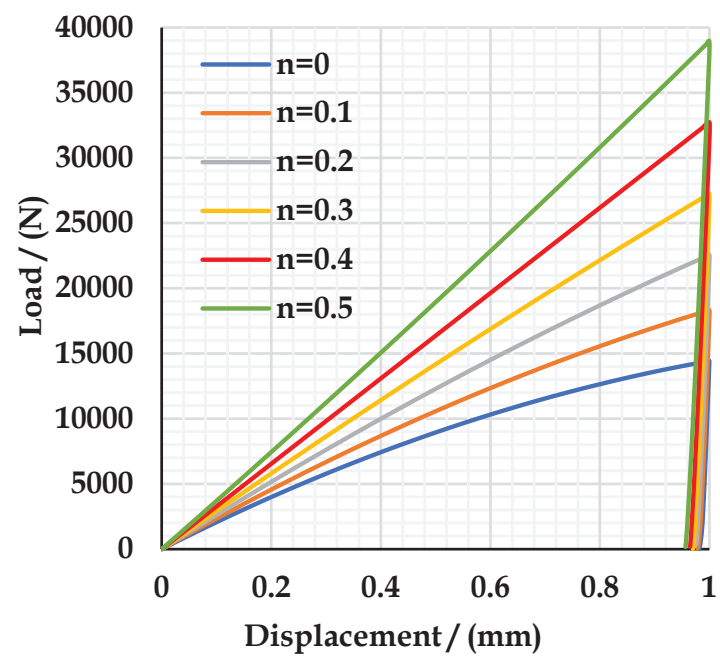

Figure 16 - Load-displacement Curves for different Strain Hardening Exponents (for $E=$ $210 \mathrm{GPa}, \sigma_{y}=350 \mathrm{MPa}$ and $\alpha=7$ )

Considering the variation of load-displacement curves, it can be said that the maximum value of the loading curve increases with the increasing of the strain hardening exponent of the structural steel material.

To identify the variation of BHN with the strain hardening exponent, BHNs are calculated for structural steel materials with different strain hardening exponent values. For that, Eq. (2) and Figure 16 load-displacement curves are employed. Then, the variation is plotted and it shows that there is a good polynomial relationship between the strain hardening exponents of the steel material and the $\mathrm{BHN}$ as shown in Figure 17.

The sensitivity of BHN to the strain hardening exponent is obtained as $\frac{193.954 n^{2}+203.62 n}{96.977 n^{2}+203.62 n+123.98}$ considering Eq. (3). That means if strain hardening exponent increases by 1 unit at $n=$ $n_{0}$, BHN is going to increase by $\frac{193.954 n_{0}^{2}+203.62 n_{0}}{96.977 n_{0}^{2}+203.62 n_{0}+123.98}$ units. Figure 18 shows the variation of the sensitivity of BHN to the strain hardening exponent for different strain hardening exponent values. It shows that the sensitivity of $\mathrm{BHN}$ to the strain hardening exponent increases with the increasing of the strain hardening exponent of the steel material.

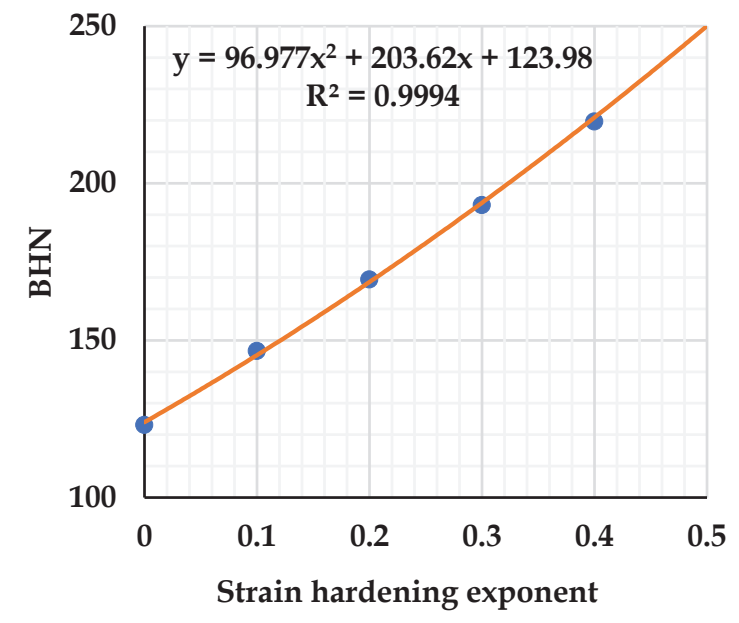

Figure 17 - Variation of BHN with the Strain Hardening Exponent

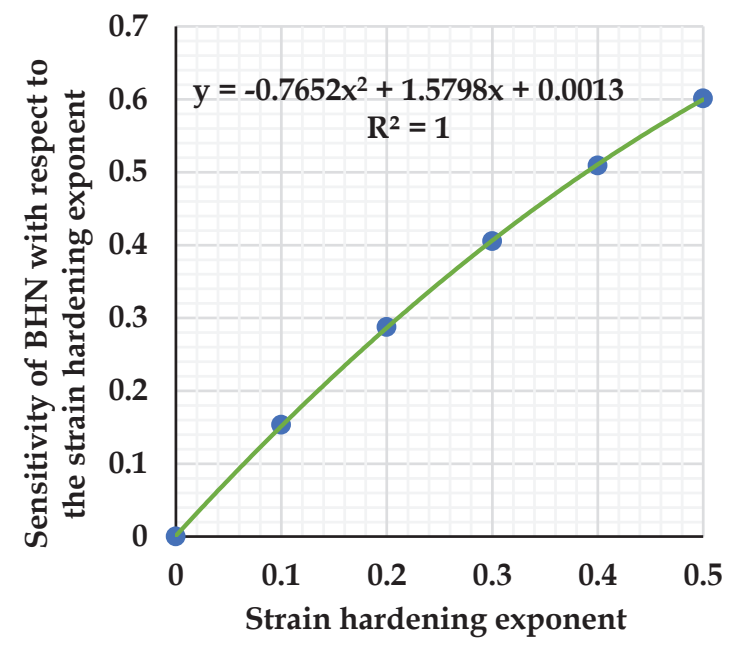

Figure 18 - Variation of Sensitivity of BHN to the Strain Hardening Exponent 


\section{5}

Comparison of the Sensitivity of BHN to Structural Steel Material Properties

Under this section, a comparison is made for the sensitivity of BHN by considering all four structural steel material properties which are discussed above. For that, variation of $\mathrm{BHN}$ with each material property (Figures 8, 11, 14, 17) is considered to select a common BHN range for all four material properties.

Table 3 gives the structural steel material property ranges considered in this study and their BHN ranges calculated from the derived relationships.

Table 3 - Structural Steel Material Property Ranges and their BHN Ranges

\begin{tabular}{|c|l|c|}
\hline \multicolumn{2}{|c|}{$\begin{array}{c}\text { Structural steel material } \\
\text { property range }\end{array}$} & $\begin{array}{c}\text { Relevant BHN } \\
\text { range }\end{array}$ \\
\hline$E$ & $190 \mathrm{GPa}$ to $210 \mathrm{GPa}$ & $165-171$ \\
\hline$\sigma_{y}$ & $275 \mathrm{MPa}$ to $400 \mathrm{MPa}$ & $138-190$ \\
\hline$\alpha$ & 7 to 23 & $169-144$ \\
\hline$n$ & 0 to 0.5 & $123-169$ \\
\hline
\end{tabular}

From the table, it can be said that BHN range 165 to 169 is common for all four material properties. Hence, the comparison is made by varying the BHN from 165 to 169. Figure 19 shows the variation of the sensitivity of BHN to each material property with the BHN.

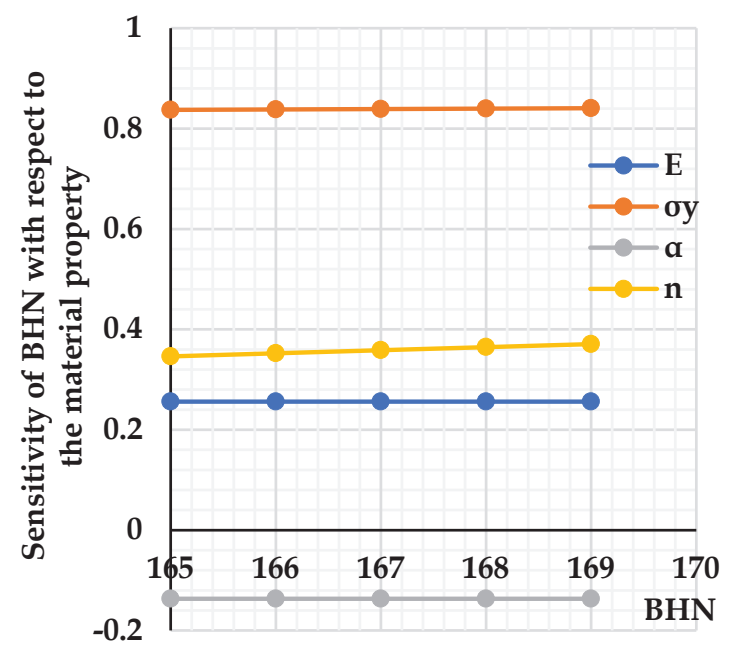

Figure 19 - Variation of the Sensitivity of BHN for Each Structural Steel Material Property

From Figure 19, it can be seen that BHN has the highest sensitivity to the yield strength and the lowest sensitivity to the $\alpha$ value of the steel material. To the Young's modulus and strain hardening exponent, the sensitivity of BHN is in the middle region and they have approximately similar sensitivity values. The sensitivity of BHN to the yield strength and strain hardening exponent is increasing with the increasing of the material property. However, the sensitivity of BHN to the Young's modulus and the $\alpha$ value is not going to change with the material property.

By considering the sensitivity behaviours of BHN to each structural steel material property, an inverse analysis method can be developed to determine the material properties, $E, \sigma_{y}, \alpha$ and $n$ of an unknown steel member using the Brinell hardness test. In that case, it is better to give more attention to the $\alpha$ value, since BHN has less sensitivity to the $\alpha$ value of the structural steel material than other properties.

\section{Conclusions}

In this study, numerical analysis has been carried out to obtain the BHN for each combination of structural steel material properties using finite element analysis. First, a 2D axisymmetric FE model is developed to simulate the indentation hardness test and validated. Then, load-displacement curves are obtained for each combination of steel material properties and BHNs are calculated using Eq. (2). Finally, the sensitivity of BHN to each material property is calculated considering the definition given in Eq. (3) and their comparison is made.

The following are the main conclusions of this study:

- The maximum value of the loaddisplacement curve and the BHN of structural steel material are increasing with the increasing of the Young's modulus, yield strength and the strain hardening exponent and it is decreasing with the increasing of the $\alpha$ value of the material.

- BHN has good power relationships with the Young's modulus and the $\alpha$ value, a good linear relationship with the yield strength and a good polynomial relationship with the strain hardening exponent of the structural steel material.

- BHN has a smaller sensitivity to the $\alpha$ value and it has the highest sensitivity to the yield strength of the structural steel material. 
- The sensitivity of BHN to the Young's modulus and the $\alpha$ value of the structural steel material are constants. That means, if the Young's modulus or the $\alpha$ value of the steel material changes by 1 unit, BHN is going to change by a constant value of units.

- The sensitivity of BHN to the yield strength and the strain hardening exponent of the structural steel material is varying with the material property value.

From this sensitivity analysis, the effect of structural steel material properties, $E, \sigma_{y}, \alpha$ and $n$ to the BHN can be identified. Therefore, our next step is to develop an inverse analysis method based on hardness test to determine material properties of an unknown steel material which has a plastic plateau in its true stress-strain behaviour. For that, we are planning to use the sensitivity analysis results of this study.

\section{Acknowledgement}

The authors would like to acknowledge licensed applications of the ABAQUS package facilitated by the Finite Element Analysis and Simulation Centre, Rubber Research Institute of Sri Lanka, Ratmalana.

\section{References}

1. Brownjohn, J. M. W., "Structural Health Monitoring of Civil Infrastructure", Phil. Trans. R. Soc. A, 365(1851), February, 2007, pp. 589-622.

2. Feng X., Li, G. and Zhou, J., "State-of-the-Art of Statistical Identification for Structural Health Diagnosis in Civil Engineering", Earthquake Engineering and Engineering Vibration, 25(2), 2005, pp. 105-113.

3. Zhang, D. and Johnson, E. A., "Substructure Identification for Shear Structures I: Substructure Identification Method", Struct. Control \& Health Monit., 20(5), 2013, pp. 804-820.

4. Jung, S.K. and Frangapol, D. M., "Prediction of Reliability and Cost Profiles of Deteriorating Bridges under Time- and Performance-Controlled Maintenance", Journal of Structural Engineering, 130(12), December, 2004, pp. 1865-1874.

5. Sherif, B., Shuichi, M. and Toshiyuki, O., "Nondestructive Damage Detection Scheme for Steel Bridges", Japanese Journal of Applied Mechanics, 9, August, 2006, pp. 63-74.
6. Withers, P. J., and Bhadeshia, H. K. D. H., "Residual Stress Part I -Measurement Techniques", Materials Science and Technology, 17, April, 2001, pp. 355-365.

7. Prevey, P. S., "Current Applications of X-ray Diffraction Residual Stress Measurement", Lambda Research, 513, 1996, pp. 103-110.

8. Steinzig, M., and Takahashi, T., "Residual Stress Measurement Using the Hole Drilling Method and Laser Speckle Interferometry Part Iv: Measurement Accuracy", Experimental Techniques, 27(6), 2003, pp. 59-63.

9. Wilson, J. W., Tian, G. Y. and Barrans, S., "Residual Magnetic Field Sensing for Stress Measurement", Sensors and Actuators A: Physical, 135, 2007, pp. 381-387.

10. Fanlin, M., Xiucheng, L., Heyun, W., Cunfu, H. and Bin, W., "Characterization of Elastic and Plastic Behaviors in Steel Plate Based on Eddy Current Technique Using a Portable Impedance Analyzer" Journal of Sensors, Article ID 8424012, 2007, 12p.

11. Rasche, S., Bermejo, R., Kuna, M. and Danzer, R., "Determination of Mechanical Properties of Brittle Materials by using the Small Punch Test and the Ball on Three Balls Test", 18 th European Conference on Fracture: Fracture of Materials and Structures from Micro to Macro Scale, January, 2010.

12. “ISO 14577: Metallic Materials-Instrumented Indentation Test for Hardness and Materials Parameters - Part 1: Test Method",1st ed., International Organization for Standardization, Geneva, 2002.

13. Zhao, M., Ogasawara, N., Chiba, N. and Chen, X., "A New Approach to Measure the Elastic-Plastic Properties of Bulk Materials Using Spherical Indentation", Acta Materialia, 54(1), January, 2006, pp. 23-32.

14. Alaboodi, A. S. and Hussain, Z., "Finite element Modelling of Nano-Indentation Technique to Characterize Thin Film Coatings", Journal of King Saud University - Engineering Sciences, 31(1), January, 2019, pp. 61-69.

15. Pharr, G. and Oliver, W., "Measurement of Thin Film Mechanical Properties Using Nanoindentation", MRS Bulletin, 17(7), July, 1992, pp. 28-33.

16. Feng, C., Tannenbaum, J. M., Kang, B. S. and Alvin, M. A., “A Load-Based Multiple-Partial Unloading Micro-Indentation Technique for Mechanical Property Evaluation", Society for Experimental Mechanics, 50(6), July, 2009, pp. 737743. 
17. Mesarovic, S. D. and Fleck, N. A., "Spherical Indentation of Elastic-Plastic Solids", Proc. R. Soc. Lond. A, 455, 1999, pp. 2707-2728.

18. Fischer-Cripps, A.C., "Use of Combined Elastic Modulus in the Analysis of Depth-Sensing Indentation Data", Journal of Materials Research, 16(11), November, 2001, pp. 3050-3052.

19. Oliver, W. C. and Pharr, G. M., "An Improved Technique for Determining Hardness and Elastic Modulus Using Load and Displacement Sensing Indentation Experiments", Journal of Materials Research., 7(6), June, 1992, pp. 1564-1583.

20. Oliver, W. C. and Pharr, G. M., "Measurement of Hardness and Elastic Modulus by Instrumented Indentation: Advances in Understanding and Refinements to Methodology", Journal of Materials Research, 19(1), January, 2004, pp. 3-20.

21. Cao, Y. P. and Lu, J., "A New Method to Extract the Plastic Properties of Metal Materials from an Instrumented Spherical Indentation Loading Curve", Acta Materialia, 52(13), August, 2004, pp. 4023-4032.

22. Cao, Y., Qian, X. and Huber, N., "Spherical Indentation into Elastoplastic Materials: Indentation-Response Based Definitions of the Representative Strain", Materials Science and Engineering A, 454-455, April, 2007, pp. 1-13.

23. Nayebi, A., Abdi, R. E., Bartier, O. and Mauvoisin, G., "New Procedure to Determine Steel Mechanical Parameters from the Spherical Indentation Technique", Mechanics of Materials, 34(4), April, 2002, pp. 243-254.

24. Le, M. Q., "Material Characterization by Instrumented Spherical Indentation", Mechanics of Materials, 46, March, 2012, pp. 42-56.

25. Pham, T. H., Phan, Q. M. and Kim, S. E., "Identification of the Plastic Properties of Structural Steel Using Spherical Indentation", Materials Science and Engineering A., 711(10), January, 2018, pp. 44-61.

26. Pham, T. H., Kim, J. J. and Kim, S. E., “Estimating Constitutive Equation of Structural Steel Using Indentation", International Journal of Mechanical Sciences, 90, January, 2015, pp. 151-161.

27. Tsukahara, H. and Lung, T., "Finite Element Simulation of the Piobert-Luders behaviour in a Uniaxial Tensile Test", Materials Science and Engineering A, 248(1-2), June, 1998, pp. 304-308.

28. Pham, T. H. and Kim, S. E., "Determination of Mechanical Properties in SM490 Steel Weld Zone using Nanoindentation and FE Analysis", Journal of Constructional Steel Research, 114(4), November, 2015, pp. 314-324.
29. Sivapalan, S., Jayasinghe, J. A. S. C. and Bandara, C., "Prediction of Residual Strain of Steel Using Brinell Hardness Number: Development and Application to Old Bridge Structures in Sri Lanka", Society of Structural Engineers, Sri Lanka, August, 2018, pp. 79-85.

30. Dao, M. et al., "Computational Modelling of the Forward and Reverse Problems in Instrumented Sharp Indentation", Acta Materialia, 49(19), November, 2001, pp. 3899-3918.

31.Smith, M., “ABAQUS/Standard User's Manual, Version 6.14., Dassault Systèmes Simulia Corp, Providence, RI, USA, 2014.

32. Brinell Hardness Tester (Model FB-1), Instruction Manual (Hydraulic type), Future-Tech Corp., U.K., 2010.

33. Arriola, L and Hyman, J. M., "Sensitivity Analysis for Uncertainty Quantification in Mathematical Models", Mathematical and Statistical Estimation Approaches in Epidemiology, June, 2009, pp. 195-247. 